\title{
Pediatric Research: Challenges to Be Met and Promises to Keep
}

\author{
JOSEPH A. BELLANTI ${ }^{(10)}$
}

\author{
The woods are lovely, dark, and deep, \\ But I have promises to keep, \\ And miles to go before I sleep. \\ And miles to go before I sleep. \\ -Robert Frost
}

Presidential Address before the Society for Pediatric Research at its Fiftieth Annual Meeting, San Antonio, Texas, USA, May 1, 1980

Members of the Society for Pediatric Research, participants in this year's combined meetings of the American Pediatric Society and the Society for Pediatric Research, members of the Ambulatory Pediatric Association, and guests.

It is a special honor and privilege for me to give this year's Presidential Address, this being the 50th annual meeting of the Society for Pediatric Research. At the outset, I should like to thank you for giving me the opportunity to serve as your President; I want to thank the Council and the entire membership for your unstinting support over the past year. I also want to express publicly my gratitude to the many people who have enriched my life: my parents who gave me the gift of life and who encouraged me always to strive for excellence; my wife and children who have stood beside me in all my work and helped me to find the joy in it; my teachers, colleagues, students, and patients, who have provided the challenges to be met and reminded me of the promises to keep.

To bring a child in the world is to make a promise to both the child and to oneself; to assume the responsibility for the medical care of children, is to accept the challenge of guaranteeing that the promise is kept. Ours is therefore a complex mission.

Often because of our scientific expertise and our experience with normal growth and development of children and their diseases, pediatricians are called upon to be the child's advocate in society. At such times, our medical and scientific expertise are directed by social, political, and personal values, for who knows better than we do what conditions best foster the growth and development of children? Sometimes, however, we cannot await the call; our special knowledge must force us into the public arena.

Not too long ago, the young of our species were a neglected, poorly understood, and often exploited population. "We know nothing about childhood," wrote Jean Jacques Rousseau, "and with our false ideas the more we do, the more we botch." For trying to correct "false ideas" about children, Rousseau was condemned by the Parliament of Paris in 1762 and would have been thrown in prison had the prince de Conti and Mme de Luxembourg not arranged for his hasty escape from Paris. The "wisest writers" about the health and welfare of children, Rousseau had written, only "look for the adult in the child and do not think of what he is before he becomes an adult."

Today, pediatrics is the direct descendent of this radical belief that children are not miniature adults. Rather, because they are not adults, children require the protection of the adult world, and for this reason, unfortunately, children have been a chronically endangered species.

Children are a valuable resource and are, ultimately, our chief reason for being. To the scientist, children's ever-changing bodies and behaviors are the riddle and wonder of life itself. At the first meeting of the American Pediatric Society in 1889. Abraham Jacobi summed up this attitude by saying that "Pediatrics deals with the entire organism at the very period which presents the most interesting features to the student of biology and medicine." No one would dispute that statement. From the roots of this fascination with the processes by which the young of our species mature springs the best research. I agree with Allan Gregg, a past president of the Society for Pediatric Research that the spirit of research must come from within; it must, as he said, be "the response to curiosity, not to need (6)."

\section{EARLY HISTORY OF THE SOCIETY FOR PEDIATRIC RESEARCH}

Our Society began as the Eastern Society for Pediatric Research and held its first meeting on March 23, 1929. Its first officers were: Dr. James L. Gamble of Harvard, President; Dr. Bengt Hamilton of Johns Hopkins, Vice President; and Dr. Charles F. McKhann of Harvard, Secretary-Treasurer (8). Let us imagine what it was like at that first meeting: Hoover was President, everyone drove a Model " $A$ " Ford, milk was $10 \notin$ a gallon, and bread was $5 \notin$ a loaf. It was a presidential election year, and there was the promise of "a chicken in evey pot, a car in every garage," and "prosperity was just around the corner." The Eastern Society for Pediatric Research had 25 members (Figs. 1 and 2). Today, the active membership numbers 606. The present officers and Council are shown in Figure 3.

Much has changed since those early years of the Society. In a sense, our country has grown up, and with it, our Society has matured. Article II of the original constitution, for instance, stated that the purpose of the Society "shall be to foster pediatric investigation and to provide opportinity for younger men to present their work." Although women had been accepted as active members as early as the 1930's, it was not until 1974 that the official statement of the Society's purpose was changed to include "younger investigators," of both sexes.

In its 50 years, the Society has grown in other ways, too. It very quickly outgrew it provincial limits, and moved beyond the banks of the Charles River. In 1932, it was no longer appropriate to call it the Eastern Society, and the term was dropped from the name. The active membership in 1944, when the Society was 15 years old (Fig. 4) was still clustered along the East Coast, however. At the 30th birthday of the Society in 1959 (Fig. 5), our destiny had marched westward.

Today (Fig. 6), not only have we increased in numbers, but we have moved westward and even beyond the boundaries of the United States to include Canada, Mexico, and Europe. Moreover, with the establishment of an international pediatric research journal in the early 1960's, the growth of the Society has also been measured in terms of the effective alliance of pediatric investigators throughout the world, including members of the American Pediatric Society, the European Society for Pediatric Research, and most recently, the Latin American Society for Pediatric 


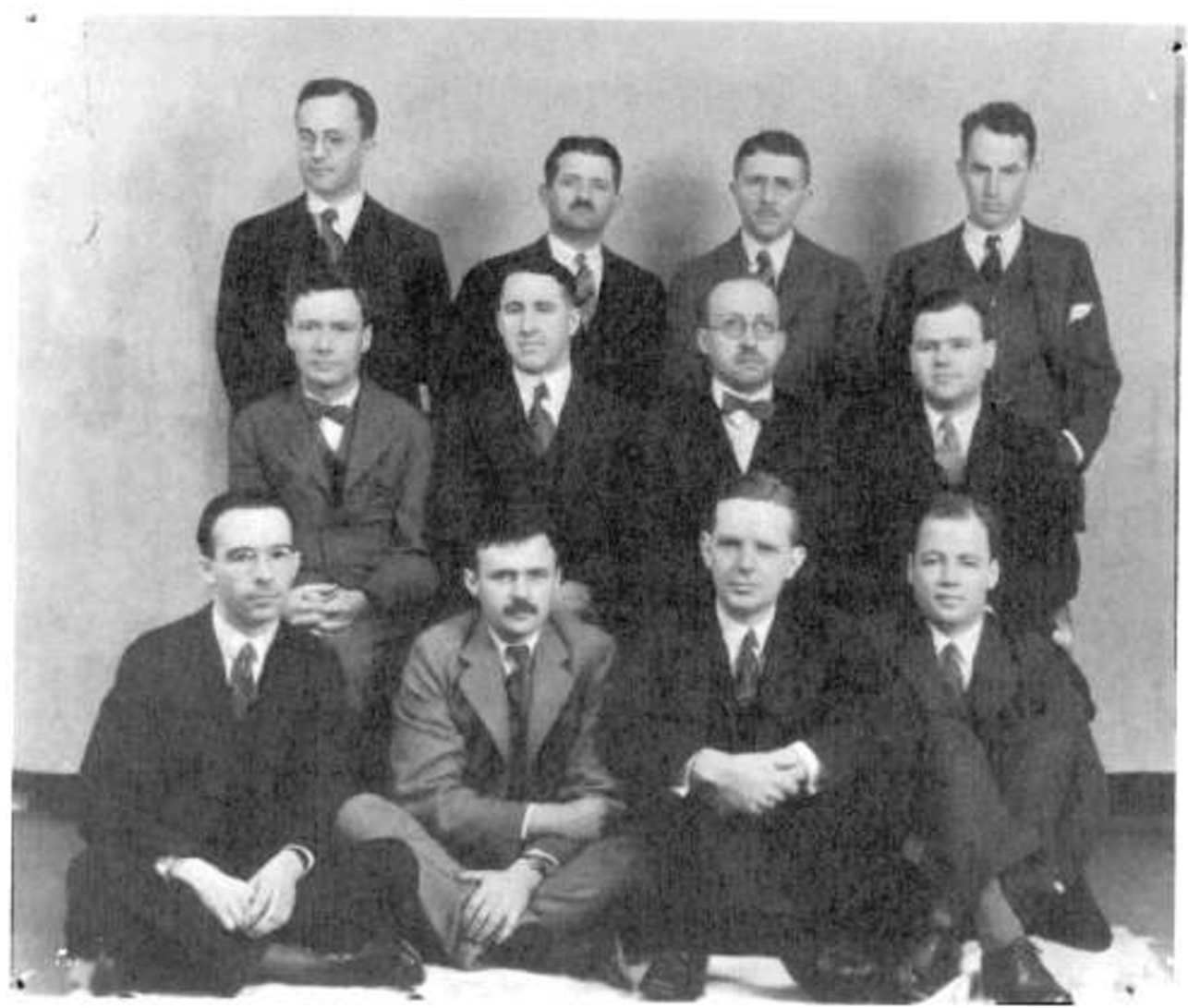

Fig. I. Top row: Darrow, Levine, Weymuller, Butler; Middle row: Gamble, McQuarrie, Drake, McKhann; Bottom row: Bridge, Josephs, Wilson, Wilder.

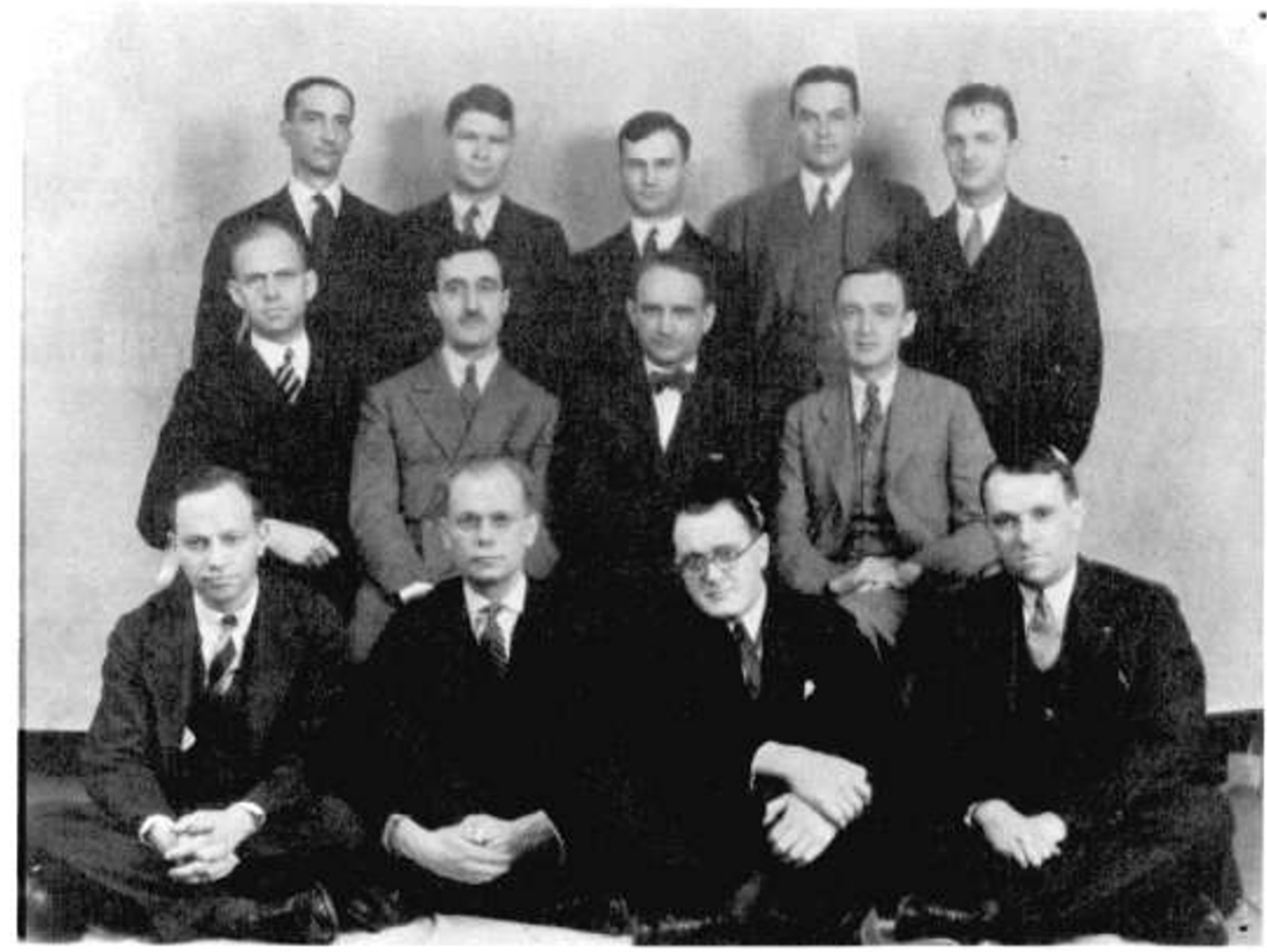

Fig. 2. Top row: Trask, Holt, Guest, Stokes, Johnston; Middle row: Hoag, Stuart, Hamilton. Lawson; Bottom row: Mclntosh, Byers, Anderson, Higgins.

Figures 1 and 2 are photographs of the original officers and membership of the Society for Pediatric Research in 1929. (Reproduced from Ref. 3 with permission from the publishers). 


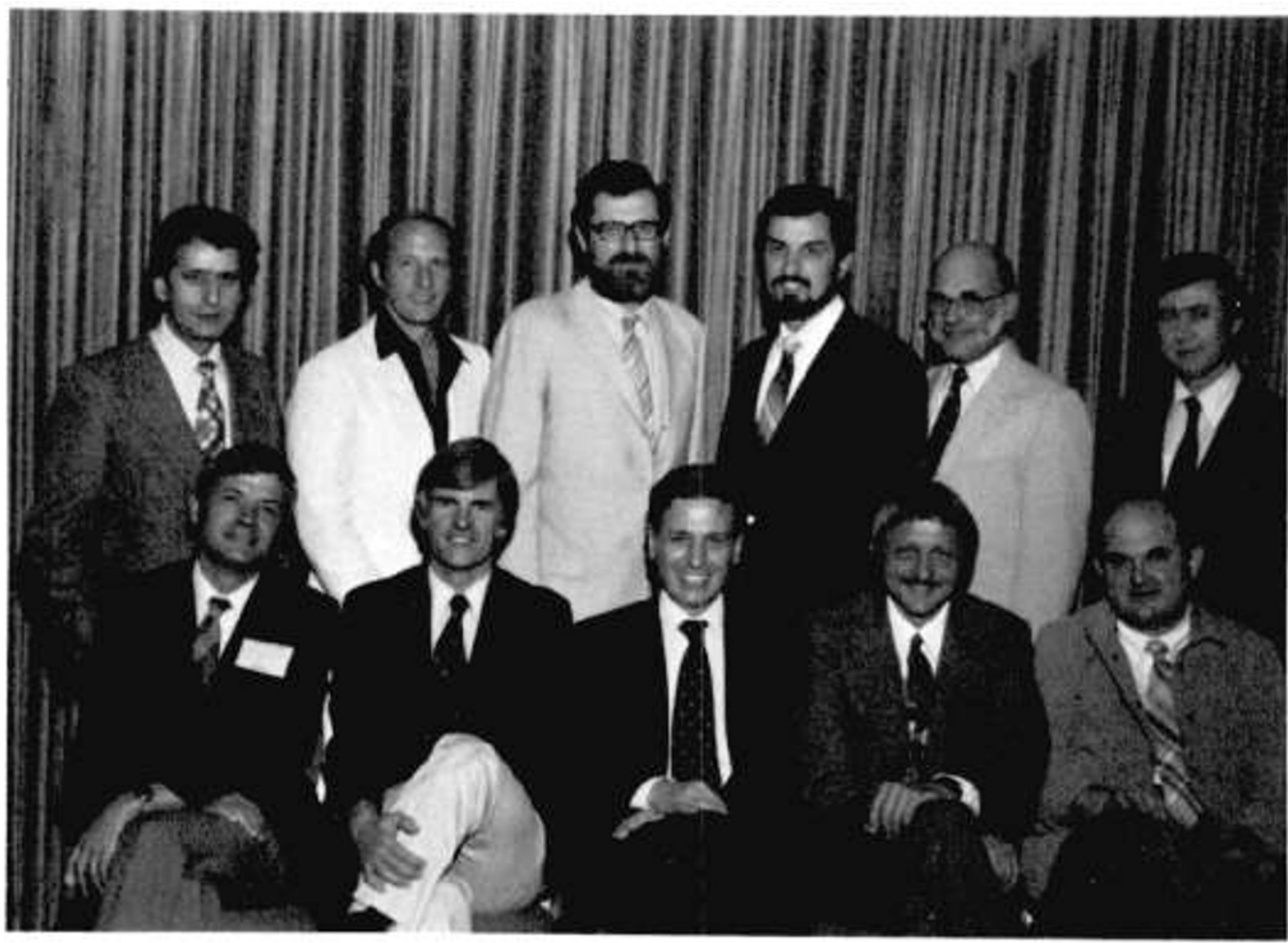

Fig. 3. Photograph of the current officers and members of the Council of the Society for Pediatric Research in 1979-1980. Top row (left to right): Dr. Pearay L. Ogra, Dr. Harry L. Greene, Dr. Charles S. August, Dr. Thomas F. Boat, Dr. Sanford Cohen, Dr. Mark A. Sperling; Bottom row (left to right): Dr. John D. Johnson, Dr. Richard B. Johnston, Jr., Dr. Joseph A. Bellanti, Dr. Robert L. Baehner, Dr. Normal J. Siegel. Absent from photograph: Dr. Anne A. Gershon, Dr. Michael M. Kaback, Dr. Allen H. Neims.

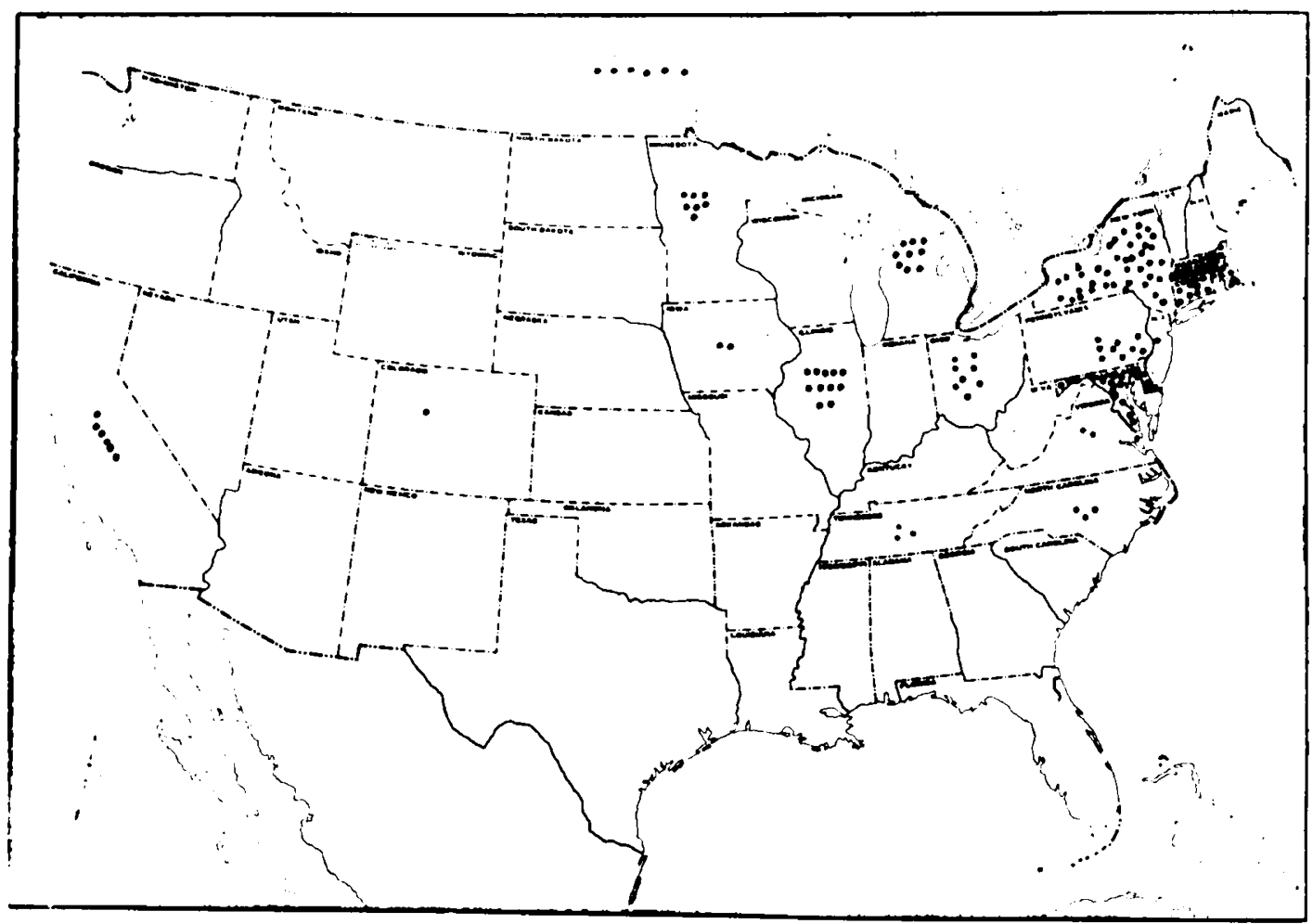

Fig. 4. Distribution of membership in 1944. (Reproduced from Ref. 3 with permission from the publishers).

Investigation. Our growth is also reflected in the numbers of papers submitted to the Society for publication (Table 1), shown here as average yearly submission rates in corresponding years. From 1929 to the present, there has been a progressive increase in the number of papers submitted, ranging from 18 in 1921 to 1082 in 1980.

From these impressive figures, one would conclude that all is well in the research community; investigators are busy in their 
laboratories and with their manuscripts. This, unfortunately, is not the case.

\section{IMPORTANCE OF RESEARCH IN THE TEACHING ENVIRONMENT}

Today, our Society faces a number of challenges, not the least of which is the dwindling number of clinical investigators. At the
1979 annual meeting of three major research societies-the American Federation for Clinical Research, the Association of American Physicians, and the Society of University Surgeons - the Presidential Addresses focused on the diminished numbers of clinical investigators. Again in 1980, this year's clinical meetings will also raise this issue. Thus, there appears to be considerable interest shown by several organizations including our own in

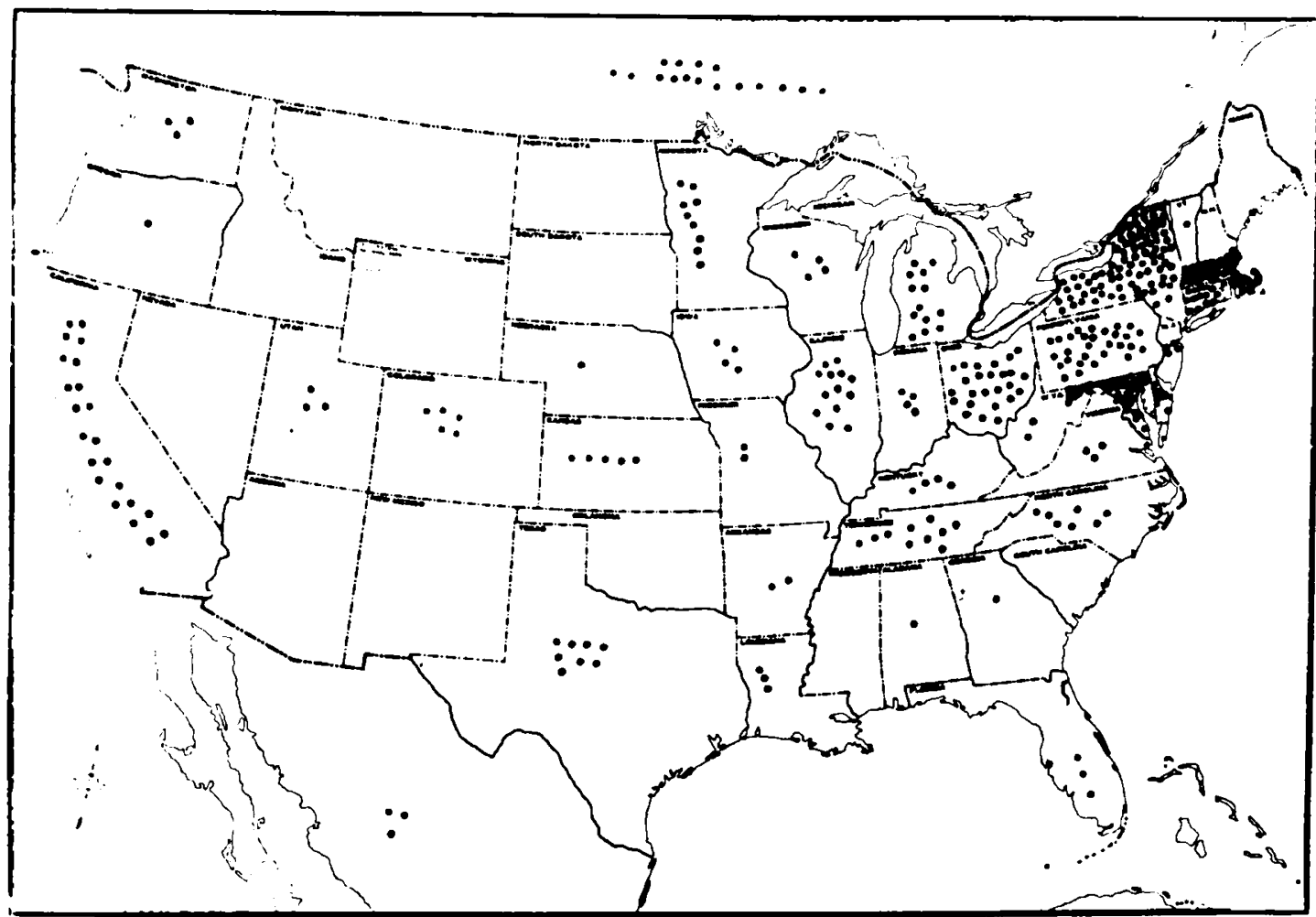

Fig. 5. Distribution of membership in 1959. (Reproduced from Ref. 3 with permission from the publishers).

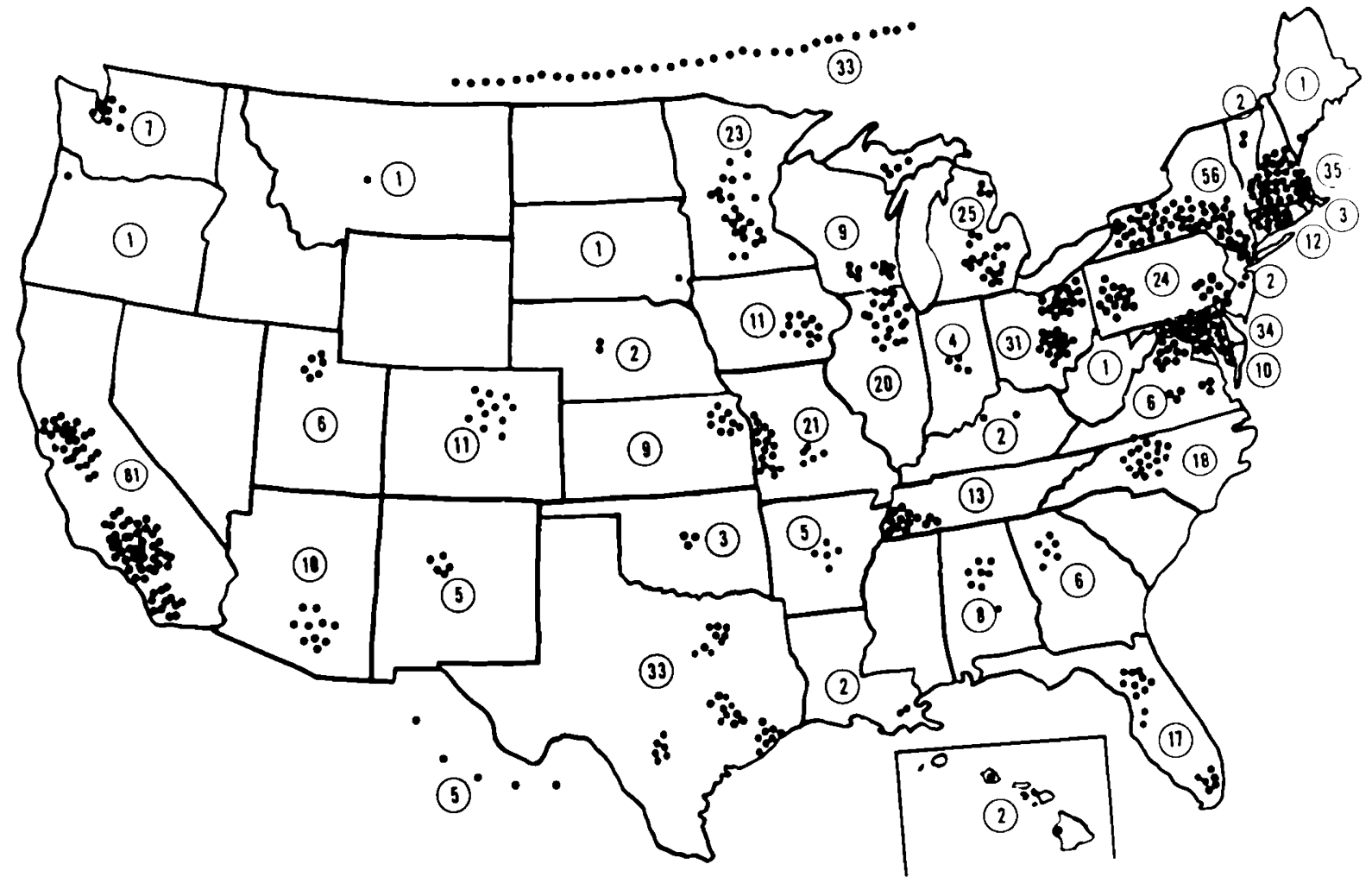

Fig. 6. Distribution of membership in 1980. 
Table 1. Number of papers submitted to the Society for Pediatric Research (average per 5-year period or total per year)

\begin{tabular}{cc}
\hline Yr(s) & No. of papers \\
\hline $1929-1933$ & 18 \\
$1934-1938$ & 29 \\
$1939-1943$ & 43 \\
$1944-1948$ & 37 \\
$1949-1953$ & 75 \\
$1954-1958$ & 128 \\
$1959-1963$ & 257 \\
$1964-1968$ & 337 \\
$1969-1973$ & 563 \\
$1974-1978$ & 785 \\
1979 & 998 \\
1980 & 1082 \\
\hline
\end{tabular}

seeking solutions to the problems responsible for the acute shortage of physician-investigators (7).

The importance of research in the teaching environment cannot be overemphasized. Every young medical student and practitioner should strive to keep that sense of curiosity, otherwise known as research, alive. Without it, even the practice of medicine becomes lifeless, dull, and stale.

However, in recent years, it has become increasingly difficult to keep a hand in research and a hand in clinical work. A wedge has been driven between the laboratory research worker and the practicing clinician. The number of MD's in research has been going down, and the number of Ph.D's has been going up. A recent report on Clinical Research Manpower, published by the Association of American Medical Colleges, concluded that medical student interest in research is declining, and the number of physician-investigators who might serve as role models for those students is likewise declining.

There are many reasons for this shift in the demography of medical research. Today, research is big. It requires great sums of money; it requires expensive and sophisticated research equipment and the personnel to operate it; it requires the single-mindedness of purpose necessary for carrying out extensive and complicated research programs and for maintaining the administrative structures necessary for generating a continuous string of grants. The clinician is often shut out of this field simply because clinical responsibilities overwhelm the physician's time. Research has become a full-time medical specialty.

I think this is wrong. First, the rigorous application of the scientific method is not a ritual to be practiced exclusively at the altars of the laboratory bench. The community at large is surely just as much a laboratory in which natural experiments are performed daily. In the last century, the physician was an eager observer of those experiments. Today, the research investigator tries to lure some of them into the artificial environment of the laboratory. Much is learned from the isolation of single factors for study in the laboratory, but the cost of such research is high, and much, too, is lost in the process.

\section{TYPES OF RESEARCH: PREDICTIVE AND PHENOMENOLOGICAL APPROACH}

What kinds of research do we need? We may divide research into two types. First, there is predictive research, in which the basic scientist builds conclusions inductively from the bottom up. The goal of this research is to accumulate discrete facts and to incorporate as many of them as possible into coherent theories. The best theory is the one that covers the largest number of pieces of information without unduly distorting them. The second type of research is the phenomenologic approach of the clinician. Here the strategy is to analyze the health status and behavior of that complex biological entity, the patient, by asking questions in a deductive way.
We need both kinds of work. Clinical research can too readily become the highly targeted, mission-oriented research program. Pure research suffers under such a regimen. On the other hand, pure research without the secure anchor in clinical experience can be pointless. Surely even the purest research must have its mission, for ultimately the knowledge gained in research should be fruitfully applied in practice.

Nothing human should be foreign to us. We should be students of human behavior and human nature, in sickness and in health. Almost a hundred years ago, William Osler said in his address to the American Pediatric Society, "In the cultivation of a specialty as an art there is a tendency to develop a narrow and pedantic spirit." As Osler's life and work show, however, scientific discipline and scholarly breadth need not be mutually exclusive.

\section{PROBLEMS FACING PEDIATRIC RESEARCH}

These are difficult times for research workers. Sources of difficulty are two-fold. The first is economic; it will come as no surprise to anyone when I say that money is tighter now than it has been in the past. However, the second source of difficulty is that those who dispense the limited research funds and establish priorities for research are imposing their own biases on the entire system of research. In the face of severely limited resources, individuals who make research policy at the national level favor research that promises a readily discernable pay-off. The reward need not be immediate, and the research program can go on for decades, but the goal of the program must be simple enough to be quickly grasped in the conference rooms of the funding agencies and in the halls of Congress. Political and rhetorical exigencies, not research, have reduced complex problems to "Conquer Cancer" or "Immunize the Entire Population."

In the face of scientific uncertainty, with which we are all familiar, and economic uncertainty, with which we are becoming familiar, we cannot give way to despair. The chief challenge we face as research workers is to maintain and sustain the best scientific inquiry. To do this, we need to be resourceful.

I believe that quality research will always be funded, but that depends on how quality research is defined and by whom. We need to learn new ways of raising the necessary research funds. Already major support is coming from sources other than the federal government. The National Institutes of Health and other agencies of the federal government still fund $81 \%$ of the research investigators in our Society. Nevertheless, $19 \%$ of us are currently receiving funds from nonfederal sources: the March of Dimes, the National Kidney Foundation, the Diabetes Foundation, the Cystic Fibrosis Foundation, and several private foundations. We should encourage this movement and diversify our portfolios as much as possible. The time is past when we can comfortably depend upon a single source of funds.

We pay a price for this diversity, however, for the research worker today must be a bit of an entrepreneur. Competition is now keen for the dwindling resources, and the administrative details upon which a major research group must depend threaten to overwhelm the reason for the group's existence-that is, the research itself. Top researchers, having risen to the top of their fields by dint of hard work and scientific imagination, find themselves out of their laboratories and into offices. More and more, they must take responsibility for preparing grant proposals, preparing for site visits, overseeing the research operation, and acting as liasion between the laboratory and the funding agency.

A recent AAMC report (2) has stated:

Biomedical science today is in a crucial stage. Research funding has barely kept pace with inflation for the last decade, while investments in training funds have created a very large pool of capable young scientists. As a result, the $\mathrm{NIH}$ has in recent years been able to fund only $30-40$ percent of approved grant applications. Each year, 10-12 percent of the pool of "principal investigators" are new, but in the relatively stable state in which research finds itself, an equivalent percent of the previous years' principal investigators 
"new" to the system in 1966 and 1968 showed that 50\% had disappeared in five years. The loss is composed of scientists who were, for the most part, highly creative and productive, but who could not meet the extraordinary high standards that prevail, especially in circumstances of severe financial stringency.

The attractiveness of any career diminishes sharply when the chances for advancement or even survival become small. There has been an alarming decline in the number of physicians seeking training in biomedical science over the last 3-5 years, a signal that this group has "read the tea leaves" and already "opted out" to pursue careers in medical practice. The failure to renew the pool of clinical investigators bodes ill for the future of medical science at least. These are the scientists who built bridges between advances in the preclinical biological sciences and the problems encountered at the bedside of the patient. They are usually the ones who recognize the infrequent "experiments of nature"-unique and rare variants in spontaneously occurring human diseaseand exploit the opportunity these offer to illuminate new approaches to problems in basic biological science. The discouragements of physicians with the possibilities for careers in research will soon be followed by comparable perceptions and responses in other scientists who aspire to research careers in the biosciences.

As young scientists become discouraged, research funds will increasingly be controlled by older and less competitive scientists, with a gradual diminution in innovation and a slow deterioration in quality. Externally, there is likely to be little perception of change. Grants will be made, research will be conducted, papers and books will be published. But this will in reality be the triumph of "form," covering up the strangulation of "substance."

\section{SUBSTANCE AND PROCESS}

We must make a clear distinction between substance and process of what we do as research workers. Substance refers to the essence of something; process is what brings it about. Washington D.C., where I work, is a community built on process. There is a judicial process, a legislative process, a budget process-a process for everything. It goes without saying, the more sophisticated the process, the more mystifying the product. Some processes are so Byzantine, in fact, that it is indeed very difficult to identify the product at all. An editorial in the Washington Post recently announced, wryly, that "Process is our most important product" (4). Scientific research cannot afford such a tautology.

I do not mean to minimize the importance of orderly procedures. I would warn the administrator, however, to avoid the trap of being absorbed in the process and losing sight of the substance of the work. As an example, a recent editorial in Science addresses the problem of the diversion of funds for research to increased administrative personnel and support (3).

Because of these concerns, the Society for Pediatric Research Council has surveyed its membership to develop a comprehensive data base from which we might develop a coherent strategy for expanding research and training support. In February of this year, a questionnaire was circulated to all active and emeritus members of the Society. The results of this survey are given in Tables 2 to 4.

\section{THE HEALTH CARE SYSTEM AND THE ROLE OF RESEARCH}

We see from the survey that we need to deal with a regular alphabet soup of government agencies: NICHD, NCI, NHLBI, NIAID, NIAMDD, and so forth. There is no avoiding it: we must deal with the federal bureaucracy. Of course, no one enjoys dealing with the bureaucracy. Our work is with patients and in research, but deal with it we must, and so we should take a moment to examine the system and to define our place within it.

Policy, research, and regulation are all closely interrelated
Table 2. Results of the SPR questionnaire

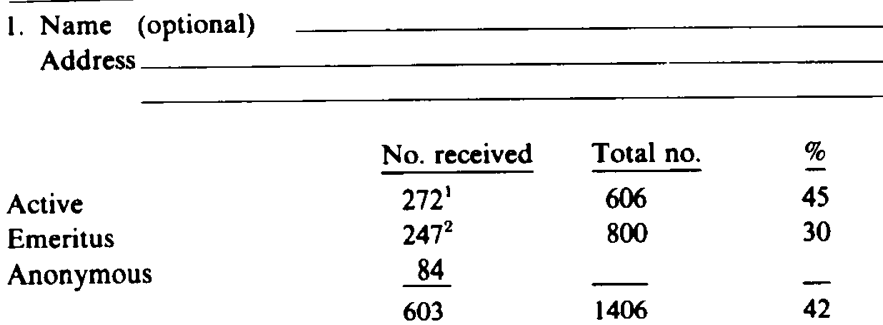

2. Are you currently receiving federal or non-federal support for research or training in pediatric research?

\begin{tabular}{|c|c|c|c|}
\hline & Yes & No & Total \\
\hline Active & $247(91)^{3}$ & $\overline{25(9)}$ & $\overline{272}$ \\
\hline Emeritus & $187(76)$ & $60(24)$ & 247 \\
\hline \multirow[t]{3}{*}{ Anonymous } & $55(65)$ & $29(35)$ & 84 \\
\hline & $489(81)$ & $114(19)$ & 603 \\
\hline & Federal & Non-Federal & Total \\
\hline Active & $212(86)$ & $35(14)$ & 247 \\
\hline Emeritus & $146(78)$ & $41(22)$ & 187 \\
\hline \multirow[t]{2}{*}{ Anonymous } & $40(73)$ & $15(27)$ & 55 \\
\hline & $\overline{398(81)}$ & $91(19)$ & 489 \\
\hline
\end{tabular}

${ }^{1}$ Includes 9 Canadian members.

${ }^{2}$ Includes 3 Canadian members

${ }^{3}$ Percentage.

Table 3. Results of the SPR questionnaire (continued)

3. If the answer to the above question is yes, which federal agency?

\begin{tabular}{|c|c|c|c|}
\hline & Active & Emeritus & Anonymous \\
\hline NICHD & 89 & 52 & 10 \\
\hline $\mathrm{NCI}$ & 21 & 12 & 8 \\
\hline NHLBI & 38 & 40 & 16 \\
\hline NIAID & 32 & 28 & 5 \\
\hline NIAMDD & 43 & 24 & 3 \\
\hline NINCDS & 10 & 4 & 4 \\
\hline NIGMS & 22 & 5 & 1 \\
\hline NEI & 1 & 3 & 0 \\
\hline NIEHS & 2 & 0 & 0 \\
\hline NIA & 2 & 1 & 3 \\
\hline NIDR & 0 & 2 & 1 \\
\hline NSF & 1 & 1 & 0 \\
\hline DOD & 0 & 1 & 0 \\
\hline OTHER & 0 & 0 & 0 \\
\hline
\end{tabular}

4. List the title(s) and the grant number of all funded research. Variable response

5. What non-federal support are you receiving? Which agency? Variable (National Foundation, March of Dimes, Diabetes Association, Cystic Fibrosis Foundation, National Kidney Foundation, American Heart Association, State and City support, Private Foundations, Pharmaceutical Companies.)

6. If you are not receiving support, have you been approved but not funded in the last 5 to 7 years? Yes___No___ If yes, which agency?

\begin{tabular}{lccc} 
& Yes & No. received & \\
\cline { 2 - 3 } Active & 43 & 272 & 16 \\
Emeritus & 42 & 247 & 17 \\
Anonymous & 31 & 84 & 37
\end{tabular}

' The agencies cited reflect those providing major funding, i.e., NICHD, NIAID NIAMDD, NHLBI, NCI, and NIGMS

events (Fig. 7). Policy is effected by the Congress in response to the stated and perceived needs of the American public, the pressure of special interest groups, and the influence of powerful individuals. Ultimately, Congress should serve the needs of the 
Table 4. Results of SPR questionnaire (ctd)

7. What is your area(s) of research interest?

\begin{tabular}{|c|c|c|}
\hline & Active & Emeritus \\
\hline Adolescent medicine & 1 & 1 \\
\hline $\begin{array}{l}\text { Behavioral sciences and health services re- } \\
\text { search }\end{array}$ & 6 & 13 \\
\hline Cardiology & 14 & 24 \\
\hline Developmental biology & 5 & 7 \\
\hline Developmental pharmacology & 12 & 4 \\
\hline Endocrinology & 17 & 19 \\
\hline Epidemology & 0 & 0 \\
\hline Gastroenterology and nutrition & 11 & 9 \\
\hline General pediatrics, education and training & 4 & 24 \\
\hline Genetics & 23 & 17 \\
\hline Hematology and oncology & 24 & 17 \\
\hline Immunology & 25 & 13 \\
\hline Infectious disease & 20 & 33 \\
\hline Metabolism & 43 & 21 \\
\hline Morphogenesis & 2 & 1 \\
\hline Neonatology & 33 & 14 \\
\hline Nephrology & 15 & 12 \\
\hline Neurology & 9 & 7 \\
\hline \multirow[t]{2}{*}{ Pulmonology } & 8 & 11 \\
\hline & 272 & 247 \\
\hline
\end{tabular}

8. Do you serve on any federal or non-federal research or training committees or councils? If so, specify which.

Research and training committees Council Ad hoc

\begin{tabular}{|c|c|c|c|c|c|}
\hline & \multicolumn{3}{|c|}{ Research and training committees } & \multirow[t]{2}{*}{ Council } & \multirow[t]{2}{*}{ Ad hoc } \\
\hline & Unspecified & Federal & Non-federal & & \\
\hline Active & 24 & 26 & 24 & 3 & 17 \\
\hline Emeritus & 29 & 26 & 16 & 11 & 11 \\
\hline
\end{tabular}

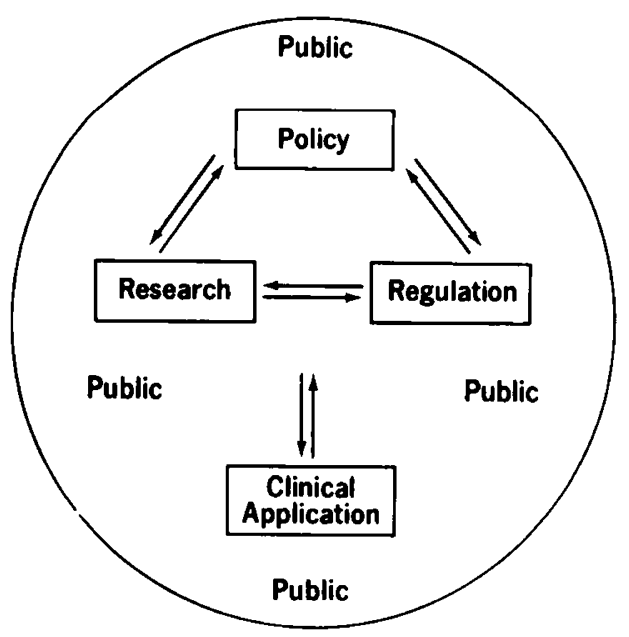

Fig. 7. Schematic representation of the interrelationships of policy, research, regulation, and clinical application and the interface of the public at all levels.

people by being well informed and by authorizing appropriations for proper research. This introduces the first of the two pivotal functions of research. It is to furnish legislators with the information they need for authorizing programs of further research and training. The second function of research in this context is the generation of new knowledge. This new knowledge in turn serves as the basis of any judgments of clinical application.

The executive side of our government is also very important. The regulators write the standards that protect the public from harm. They also rely on research data as a basis for quality decision making. Without good data furnished by accurate and reliable research devoted to socially relevant issues, however, neither can the regulatory side of the triangle function adequately.

Finally there is the public itself. The public interacts with the legislators, researchers, and regulators at all levels. The American people are the benefactors of most of the research that is carried out and financed by our tax dollars, and the American people are the beneficiaries of the improved medical care based on research.

However, there are gaps in the system in which policy, research. and regulation interrelate so closely. Good policy can only emanate from good data. Too often, the research community does not assume its rightful responsibility in presenting data and perspective to aid in determining the course of federal programs. Too often, the research workers are too naive about how to get things done. Too often, they are not political enough to be heard in the halls of Congress. Too often, they simply do not know the language for talking to the politicians who establish policy. All this is changing and must continue to change. We are no longer privileged inhabitants of an Ivory Tower. Knowing how to proceed in such a system is now an important part of our work.

\section{NEW CHALLENGES}

We are faced with new challenges today. However, today, as in the past, children are dying because they lack a political voice.

Most of the other special interest groups have an identifiable political constituency. Cancer, heart disease, stroke-all have their rallying flags, but our subjects are too young to speak for themselves. Many of them are too young to walk. Every institute of the $\mathrm{NIH}$, except one, has a disease in its name: National Cancer Institute, National Institute of Allergy and Infectious Diseases, National Institute of Arthritis and Metabolic Diseases, and so on. The National Institute of Child Health and Human Development, on the other hand, is devoted primarily to studies of normal health and human development. As Representative Fogarty said, "Who dies of human development?"

Nobody does, but the point is that you can die from a lack of development.

And yet, the makers of public policy affect the lives of children every day in the decisions they render. When they fail, because of the limitations of medical knowledge or clumsy communication of medical knowledge to policy makers, whole cohorts of Americans are damaged. This is a cost the policy makers should be able to reckon.

Medicine is not infallible. We have made grave errors in the past and will certainly make mistakes in the future. It was thought in the 1940's, for example, that if a baby was blue, a little oxygen was good treatment. If a little oxygen was good, then a lot more would be better. The tragic result was a whole cohort of babies with retrolental fibroplasia and blindness. The treatment of status thymicolymphaticus around the turn of the century by irradiation of the thymus and the iatrogenic cancers of the thyroid it produced is yet another example. The use of diethylstilbesterole to enhance fertility and wholesale tonsillectomies offer further examples. This list could go on and on.

Nor are the makers of public policy infallible. By public policy, seven vaccines are recommended for routine use in all children: diphtheria and tetanus toxoids, pertussis, polio, measles, mumps, and rubella vaccines.

Each of these vaccines in present use has associated with it a small but measurable incidence of untoward effects. The risk is so small, however, that the benefit/risk ratio is sufficiently comfortable to warrant mass administration. The case of the swine flu incident, however, raises a completely different set of questions. Some have said that the decision to immunize "every man, woman, and child" was a politically expedient decision. Let us examine the process involved in that decision. Only a very limited number of disciplines were involved, and with hindsight, it is now clear that the program was ill conceived and not medically indicated. Researchers lulled into silence did not fully participate in this process and public policy led the American people astray. More- 
over, the public was conspicuously absent in this decision which required for its success a significant mobilization of the nation. Subsequent to the cessation of the ill-fated program resulting from the unexpected complications of the Guillian-Barre Syndrome, when asked by Senator Edward Kennedy what he (Dr. Ted Cooper) would have done differently if he had to do it all over again, Dr. Cooper, then Assistant Secretary of Health, replied that

The most important thing would have been a more comprehensive widespread discussion with all sectors of the public ... so that everybody could understand what the scientific information was and what the anticipated types of problems were (5).

If we are going to require that large segments of the population continue to be immunized, then we must be prepared not only to arrive at such decisions in a broad-based manner but also to address the question of liability to compensate for the rare but unfortunate injuries associated with immunizations. This is relevant not only to the routine use of currently available vaccines but also to pediatric research required for the development of new vaccines. This becomes even more complex when the subjects involved are children, with whom we must deal with the issues of informed consent.

Yet, we may be hopeful. There are some bright signs on the horizon. Over the past year, two groups have taken a leadership role in addressing these problems. A Research Committee of the American Academy of Pediatrics directed by Dr. Moses Grossman and a group of pediatric researchers under the guidance of Dr. Joseph St. Geme have organized to increase the funding possibilities for pediatric research. I should also like to acknowledge the assistance of Mr. James Murphy who has provided the Society with invaluable counsel over the past several years. The results of our survey will provide a very important data base for these groups, and I am grateful to the membership for their cooperation and support.

Pediatric research: challenges to be met and promises to keep!! The promise of pediatric research is the promise of pediatrics which is to assure that the health of children flourishes and is attended to by professionals with competencies and skills neces- sary to address the problems of mothers and children. The challenge of pediatric research is to guarantee that the promise is kept.

The challenges are before us. In the 1980's and in the ensuing decades, the pediatric investigator will have a dual responsibility. One is scientific; the other is social. First, as a researcher at the cutting edge of science, the research investigator must take an active role in identifying substantive issues and new areas for pediatric research to advance medical science. Second, the research investigator must also assume the responsibility as physician-educator and child advocate in order that children might prosper on this earth.

This is the challenge and the promise of pediatric research.

Thank you.

\section{REFERENCES AND NOTES}

1. The privilege of being President of the Society for Pediatric Research provides the opportunity for innovation in the program of the annual meeting. This year, we elected to hold a symposium entitled, "Frontiers of Pediatric Research and the Shaping of Public Policy." The objective of the Symposium and of the Presidential Address is to invite reflection on the nature of the challenges currently facing pediatric research, how pediatric research policies are formulated. and new opportunities which are provided in linkages with the community.

2. AAMC Staff Analysis and Critique of the Health Science Promotion Act of 1979 (S.988) Memorandum 80-7. February 6. 1980

3. Abelson, P. H.: Diversion of funds from research. Science (Wash. D. C.), 208 $353(1980)$

4. Beddow, R.: Undue process ... Editorial. Washington Post. May 5, 1979.

5. Bellanti, J. A.. and Melnick, V. J.: Symposium on public concerns of immunization. Pediatr. Res. 13: 671 (1979).

6. Blackfan, K. D.: Past presidents of the American Pediatric Society 1888-1938 President's address. Am. J. Dis. Child. 56: 1 (1938)

7. Clinical Research Manpower. The Report of the Ad Hoc Committee on Clinical Research Training. Association of American Medical Colleges. February, 1980

8. Gellis, S. S.: The Society for Pediatric Research. Am. J. Dis Child., 98: 545 (1959).

9. I am indebted to Dr. Theodore S. Wilder who provided the original photographs for Figures 1 and 2, to Dr. Doris Merritt and Dr. Harvey A. Wichman for their advice in the survey, and to Dr. Robert N. Ross for his assistance in the review of the manuscript.

10. Requests for reprints should be addressed to: Dr. J. A. Bellanti, International Center for Interdisciplinary Studies of Immunology, Georgetown University School of Medicine, Washington, D. C. 20007 (USA). 